\title{
Status of Astronomy at Mbarara University of Science and Technology
}

\author{
Simon Anguma and Edward Jurua \\ Department of Physics, \\ Mbarara University of Science and Technology, \\ P.O. Box 1410 Mbarara, Uganda \\ email: simonanguma@yahoo.com, ejurua@gmail.com
}

\begin{abstract}
In this paper, we describe the role astronomy has played in interesting students towards taking physics as a major subject during their final year in Mbarara University of Science and Technology (MUST). This has resulted into some former students from MUST taking up postgraduate studies in Astrophysics and Space Science in South African Universities. The plans to strengthen and develop Astronomy in Uganda are also discussed, and in particular, the strategies for organizing the IYA2009 are outlined.
\end{abstract}

Keywords. Keyword1, keyword2, keyword3, etc.

\section{Introduction}

Mbarara University of Science and Technology (MUST) is located in Mbarara District in South Western Uganda. It was the second public University to be established in Uganda. Other public universities in Uganda include Makerere and Kyambogo Universities which are both located in Kampala, Gulu University in Northern Uganda, and Busitema University located in Tororo town found in the Eastern part of the country. In addition to the five public Universities, there are 22 recognised private Universities and 37 public tertiary Institutions in Uganda†.

World-wide, universities have provided a "pipeline" for science and technology innovation, generating thousands of technology licenses and spinning off new technology enterprisesł. Therefore, the rôle science and technology play in economic development cannot be under-rated and universities have a direct stake in this process.

In Uganda, all the five public universities offer science and technology-related programmes, whereas most of the private universities do not offer science-related programmes. Aware of the fact that a knowledge-based economy requires scientific and technological expertise, which are both strongly influenced by the strength of training in science and technology, the Government of Uganda established Mbarara University of Science and Technology (MUST) in 1989 with the main purpose of addressing the country's human resource needs in science and technology. Being a relatively new university, MUST has currently three faculties and two Institutes, viz. Faculty of Medicine, Faculty of Science, Faculty of Development Studies, Institute of Computer Science, and Institute of Tropical Forest Conservation located in Bwindi Impenetrable Forest. The Faculty of Science was established primarily to respond to the acute shortage of science teachers in the

$\dagger$ Uganda National Council for Higher Education, www .unche.or.ug/page2.php?nid=5

$\ddagger$ Diane Palmintera (2005) Accelerating Economic Development through University Technology Transfer, www.innovationassoc.com/docs/CT_NatRpt.ExSumm.pdf 
country by training science teachers for secondary schools and other tertiary institutions. Since its inception, over 400 science teachers have graduated from the University despite the fact that very few students enroll for science combinations at the high school level. Therefore, there is need to encourage and motivate students to study science subjects and this can be achieved through the introduction of new and stimulating subjects such as astronomy and space science into the university curriculum. Fierro (1999) emphatically described Astronomy as the most appealing subject and an excellent tool for conveying scientific knowledge to young students. Besides, astronomical discoveries virtually interests everyone on the globe as astronomy is a frontier science, unlike other natural sciences, it takes the universe for its laboratory, in which physical laws and theories are applied, tested and refined at temperatures, pressures and scales unobtainable in terrestrial laboratories (Stobie 1995). It is quite exciting to deal with such monstrous quantities which are of physical reality! Furthermore, Astrophysics is not only amazing in terms of scales of quantities, but it also makes students appreciate the interpretations of mathematical representations of the physical world appropriately (Anguma \& Ayikoru 2004). It is an attractive science not only because it stretches the imagination but because it is highly interdisciplinary (Anguma \& Ayikoru 2004). Due to this interdisciplinary nature, students are trained to solve problems which give them a broader view of science; a factor vital for the creation of a scientific culture and creativity in society.

Most interestingly, astronomy can be done as a hobby, compared to other science subjects, which not many people would wish to pursue and seriously enjoy as a hobby. Amateur astronomers who enjoy the subject as a hobby at times contribute scientifically useful observations in astronomy, something uncommon with other sciences! In the light of the above background, the next section describes how astronomy has changed the students' perception towards science subjects.

\section{Astrophysics/Astronomy as a course unit in Physics Department}

Astrophysics was introduced as one of the physics course units in MUST by the first author in October 2001, after completing a six months training in astronomical data collection, analysis, and interpretation under UNESCO Pilot African Academic Exchange Programme at the South African Astronomical Observatory (SAAO) in Cape Town. Since then, the number of students opting for physics as a major subject in their final year at the university has been increasing as shown in Fig. 1.

Most students $(72 \%)$ reported that their main reason for opting for physics as a major subject in their final year was the interest and passion to pursue astronomy further in their future academic endeavours. Therefore, the introduction of Astronomy has had an impact in interesting and attracting students to offer physics during their final year. In order to further develop astronomy in MUST and the country at large, our primary target was to encourage young academics and other students to pursue further training at postgraduate level in the various fields of astronomy. Table 1, below shows the list of staff and student from MUST who have engaged in postgraduate training in astrophysics.

\section{Short-term Plans}

The immediate plans (five to ten years) include:

(a) Continued teaching of basic Astronomy/Astrophysics as a physics course for undergraduate students

(b) Advocate for increased recruitment of academic staff in Physics department so that a good number of competencies can be attracted to build the astrophysics department. 


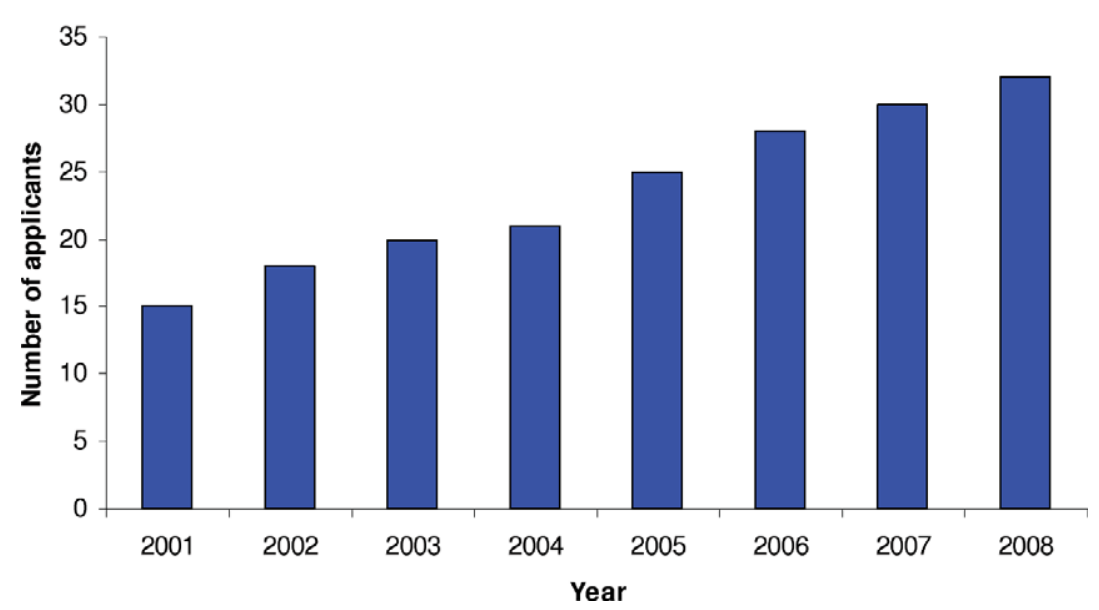

Figure 1. Number of applicants for physics major from 2001 to 2008.

Table 1. Table showing the staff and students who have engaged in postgraduate programmes in Astrophysics and Space science.

\begin{tabular}{|c|c|c|c|c|c|}
\hline & Name & Programme & Year of entry & Institution & Status \\
\hline 1 & Dr Edward Jurua & PhD Astrophysics & 2003 & Univ. Free State in S.A. & compl. 2008 \\
\hline 2 & Mr Thomas Baluku & PhD Space Science & 2004 & Univ. Kwazulu Natal & cont \\
\hline 3 & Mr J Bosco Habarulema & PhD Space Science & 2005 & Rhodes Univ. & cont \\
\hline 4 & Mr J Bosco Oruru & PhD Astrophysics & 2006 & Univ. Free State in S.A. & cont \\
\hline 5 & Mr Daniel Opolot & MSc Astrophysics & 2007 & Univ. Western Cape & cont \\
\hline 6 & Mr Oyiwoth Abedigamba & MSc Astrophysics & 2008 & Univ. Cape Town & cont \\
\hline 7 & Mr Mutambazi Tom & MSc Astrophysics & 2008 & Univ. Cape Town & cont \\
\hline 8 & Mr Amabayo Bertilus Emirant & Deg. in Ast. Space Sci. & 2009 & Univ. Cape Town & cont \\
\hline 9 & Ms Athieno Rechal & Deg. in Ast. Space Sci. & 2009 & Univ. Cape Town & cont \\
\hline
\end{tabular}

(c) Set up a modest computer laboratory implemented with most of the relevant software needed for astrophysical data reduction and analysis.

(d) Set up an Astronomy/Astrophysics library within the physics department containing the basic Astronomy/Astrophysics literature in both soft and hard copies.

(e) Initiate sustainable public awareness campaigns through both electronic and print media as well as through seminars and open days.

\section{Long-term Plans}

The long-term plans include:

(a) Strengthening the teaching of Astronomy/Astrophysics at undergraduate by reviewing the current curriculum.

(b) Introduce Astrophysics at postgraduate level and review the current curriculum to cater for postgraduate level.

(c) Start collaborative research project with SAAO (SALT) and other Universities both within and outside Africa which offer Astronomy/Astrophysics at postgraduate level.

(d) Organise school tours and Astronomy/Astrophysics open days for schools and interested members of the local communities. 
(e) Arrange astronomy contests for school children. This will motivate school children to take science subjects at secondary school and thereafter at the university.

(f) Acquire a small telescope through donations and other sources.

(g) Advocate for the integration of Astronomy in the National Curriculum for schools.

\section{The International Year of Astronomy (IYA 2009)}

The year 2009 was declared by the General Assembly of the United Nations as the International year of Astronomy (IYA2009). This is to mark 400 years of observational astronomy since Galileo Galilei used the first telescope for observations of the sky. In Uganda, Mbarara University of Science and Technology is spearheading the organisation of several events to mark the IYA2009. The main highlights of the events that characterise the IYA2009 in Uganda include:

\subsection{Astronomy for Education}

In Africa, the IYA2009 was celebrated under the theme "Astronomy for Education" and mainly targeted primary and secondary school children. For the target group, we organised the following events: Essays and quizzes for students at all levels and the winners will be awarded simple prizes as a way of motivation. Teachers will be encouraged to design models for explaining astronomical/astrophysical concepts, e.g. the Solar System, the phases of the Moon, how the solar and lunar eclipses occur and many other astronomical phenomena which can easily be modeled within a limited resource environment. The best models were awarded prizes. School tours for both primary and secondary schools will be organized to places of astronomical significance.

\subsection{Astronomy Workshop}

We organised a sensitization workshop on Astronomy. The theme of the workshop was: "Scientific awareness on Astronomy and the IYA2009". The workshop aims at achieving the following objectives:

- Equipping the participants with the basic knowledge of astronomy;

- Increasing scientific awareness by highlighting the importance of astronomy to society;

- Supporting and improving formal science education;

- Gathering the views and feelings of the people about Astronomy;

- Comparing basics of Astronomy to the African indigenous astronomical concepts;

- Using Astronomy as a tool to attract and encourage children into science subjects.

The workshop was hosted by Mbarara University of Science and Technology in September 2009. During the workshop, International speakers were invited to address thematic areas in astronomy education.

\subsection{Amateur Astronomers Clubs}

Formation of Amateur Astronomers Clubs will be encouraged and these associations will be used as platforms for sharing basic knowledge on astronomy.

\subsection{Astronomy and the Uganda National Science Week}

In September 2007, Uganda organised the first ever National Science Week (NSW), which was characterised by several scientific events. The event included conferences, visits by role models of science and technology to schools, and was crowned by announcement of research awards and Presidential Science Awards. In 2009 we organised workshops and school visits during the National Science Week as part of the events marking the IYA2009. 


\section{Conclusion}

Since the introduction of Astrophysics at MUST, both the number of students majoring in physics in the final year of their undergraduate studies as well as the number of students opting to study Astrophysics and Space Science at postgraduate level in other universities outside Uganda has continued to increase. We believe that strengthening Astrophysics as a course will attract and motivate more students into the sciences and provide the opportunity to study Astrophysics at postgraduate level within the country at low costs. We also hope that our community will benefit by understanding the unique nature of the universe and the consequences of some Astrophysical phenomenon which characterise our home in the universe. The events characterising the IYA will bring astronomy closer to the community.

\section{References}

Anguma, S. \& Ayikoru, J. 2004, in Developing Basic Space Science World-wide. A Decade of UN/ESA Workshops, W. Wamsteker, R. Albrecht and H. J. Haubold (eds) (Dordrecht: Kluwer Academic Publishers), p. 211

Fierro, J. 1999, Teaching of Astronomy in Asia Pacific Region Bulletin, 15, 16

Stobie, R. S. 1995, Astrophysics and Space Science, 230, 9 